\title{
Is Economic Regulation Possible? Arrow's Impossibility Theorem and the Management of Joint Use Infrastructure
}

\author{
Nick Wills-Johnson ${ }^{1}$
}

\begin{abstract}
Economic regulation is portrayed as the objective application of clear economic theory to data in order to develop outcomes which overcome the problems associated with natural monopoly in a non-political, unbiased fashion. However, is the appearance of objectivity only skin-deep? This paper argues that it is; that economic regulation is a form of social choice and that the need for subjective assumptions underpinning regulatory forecasts renders this social choice subject to Arrow's (1950) Impossibility Theorem. The same is true of any public-sector resource allocation process. The paper examines the consequences of this result for economic regulation using railways as a case study, and charts some potential policy options in response.
\end{abstract}

\section{Introduction}

Economic regulation is portrayed as the objective application of clear economic theory to data in order to develop outcomes which overcome the problems associated with natural monopoly in a non-political, unbiased fashion. However, is the appearance of objectivity only skin-deep? This paper argues that it is; that economic regulation is a form of social choice and that the need for subjective assumptions underpinning regulatory forecasts renders this social choice subject to Arrow's (1950) Impossibility Theorem. The same is true of any public-sector resource allocation process. The paper examines the consequences of impossibility for economic regulation using railways as a case study, and charts some policy options in response.

Section Two of this paper examines some different decision-making frameworks and explores the nature of objectivity in Australian rail regulation. Section Three describes some of the literature surrounding Arrow's Impossibility Theorem, and develops an application of the model in the context of economic regulation. Section Four explores the consequences of this model for the practice of economic regulation, and Section Five concludes with some policy recommendations and potential alternative means of making resource allocation decisions in the public interest.

\section{Bureaucratic vs Political Decision-Making Process}

In economics, resource allocation is a function of the market. With no externalities, market power, imperfect information or other market failures, it occurs as a byproduct of exchange in the marketplace, with price being the mechanism by which each resource is directed to where it is valued the most. However, in real-world economies, markets sometimes fail, and thus allocation mechanisms outside the market are also needed. Although something of a generalisation, it is possible to characterise non-market resource allocation decisions in two broad categories: ${ }^{2}$

\footnotetext{
${ }^{1}$ n.wills-johnson@curtin.edu.au View my SSRN Author page: http://ssrn.com/author=106139

2 Social conventions are a third way, which I return to in the conclusions to this paper.
} 
- Political: where the decision is made by a group via negotiation or some form of a vote. The group could be a group of elected representatives from a larger group, or in an extreme case an oligarchic power bloc or dictator.

- Bureaucratic: where the group devises a 'resource allocation function' to be optimised and delegates the task of optimisation to an agent.

The former is self-evidently a social decision mechanism, by virtue of the fact that choice is a collective decision. It involves the consideration of the preferences of all members of the group and then a subsequent resource allocation decision. In a loose sense, this is precisely how Arrow (1950) defines a social choice mechanism. However, the process is often viewed with some suspicion. Decisions made by plebiscite can be unwieldy and elected representatives might act with some goal in mind unrelated to the issue at hand, such as their chance of being re-elected. In these cases, the response is often to try and take the decision out of the political process; to devise a description of the type of outcomes parliament desires and the steps required to reach this goal, and then to leave the optimisation of this 'resource allocation function' to an objective agent. The response is not new. In the late $19^{\text {th }}$ Century, concern about the politicisation of railway decisions led to the creation of railway Commissioners, a system of governance that was to last almost 100 years.

Delegation leads to the bureaucratic method. Parliaments devise a resource allocation function, then leave the operation of this mechanism to an appointed agent from the governmental bureaucracy. The aim is to remove the social choice element, and render the decision-making process a mechanical task, whereby appointed officers collect information and derive a 'correct' answer via the application of the optimisation function. Although the appointed officers are usually provided with some degree of discretion, this is usually to allow flexibility in the way information is used in the optimisation function, not to change the optimisation function itself. If this is necessary, it remains the role of a parliament or designated minister.

The resource allocation function need not map into a single outcome. In general, the tighter the mapping, the greater the degree of bureaucratic control that is needed to prevent adverse outcomes. One might view bureaucratic control, then, as a continuum, with full control at one end and full private-sector decision-making at the other. However, in general, it is convenient to divide bureaucratic processes into two parts. The first of these is public management. Here, a government agency not only optimises the function parliament has designed, but it also then carries out the operational component as well. Many road agencies operate in this fashion, planning roads according to parliamentary guidelines and then building and maintaining the roads as well. The second is public regulation. Here, a public-sector body regulates an industry, allowing the industry to make its own resource allocation decisions, provided these do not conflict with those determined appropriate by parliament. This is most often used when there are a large number of possible resource allocation options, only a small portion of which a parliament deems unsuitable.

The aim of this paper is not to comment on the second-order decision; whether public or private sector operation of an industry/agency is the more appropriate option. Instead, the aim is bolder; to show that, in many cases, it is simply not possible to devise the function a parliament expects an agent to optimise in an objective fashion, and that attempts to do so merely result in a different version of a social decision 
mechanism. The only real difference is where decisions are made. The paper then goes on to suggest the consequences of such an arrangement, by examining a special case of the general result in social choice theory of Arrow's Impossibility Theorem. Figure One provides a diagrammatic representation of what this paper suggests occurs when social decisions are delegated away from the political process.

Figure One: Planned and Actual Delegation of Authority

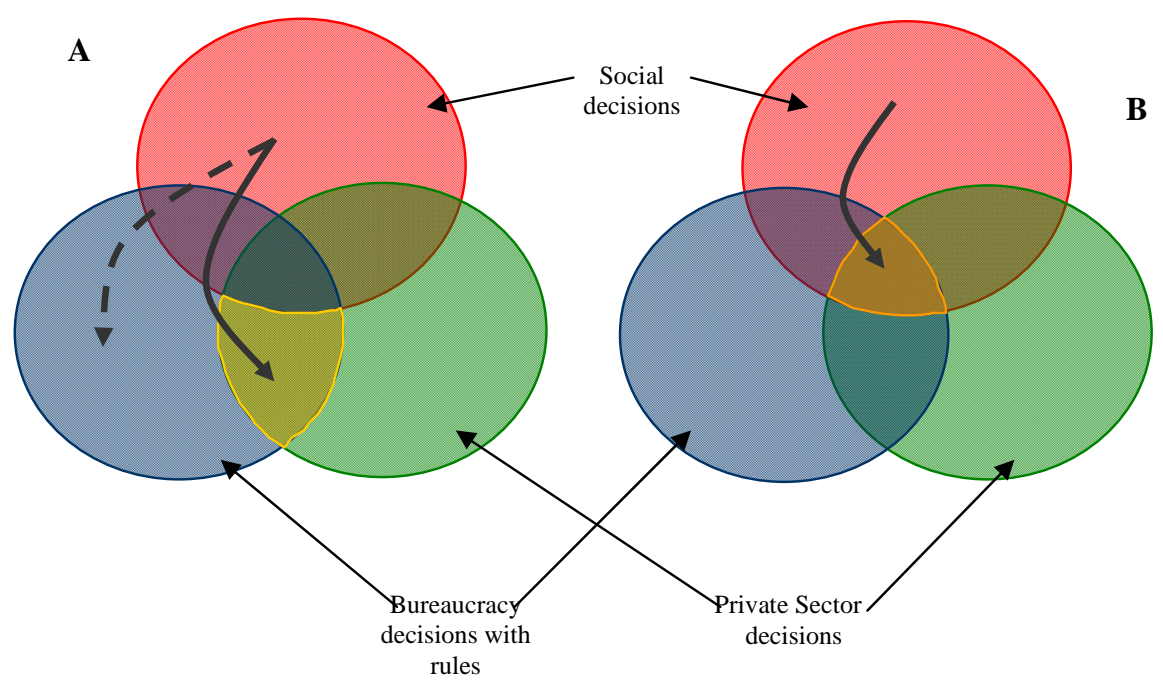

In Figure One, the intent is for delegation of authority to move decisions according to the solid (in the case of regulation) and dotted (in the case of public-sector management) arrows, as shown in the left-hand side (A). However, what actually occurs is that the delegation moves decisions to the yellow area in the right-hand side (B), where different parties might be taking the decisions, but the mechanisms for decision-making have not changed. That is, they remain social decisions, but now they take place outside the parliamentary setting.

The focus of this paper is on describing economic regulation, with a specific casestudy example in the railways sector. However, if the solid arrow in Part A of Figure One is impossible, then by extension, the dotted arrow is also impossible. Hence, the results of this paper are generalisable to a wide range of public-sector governance situations, and point towards conditions for the impossibility of objective optimisation of a function established by a parliament. Firstly, however, I describe the procedure of economic regulation of railways in Australia.

\section{The Economic Regulation of Australian Railway Infrastructure}

The resource allocation function that Australian Parliaments charge the six economic regulators with a task of regulating Australia's railways with optimising is as follows; regulators are to endeavour to minimise the economic rents available to the owners of railway infrastructure by virtue of their natural monopoly status. Diagrammatically: 


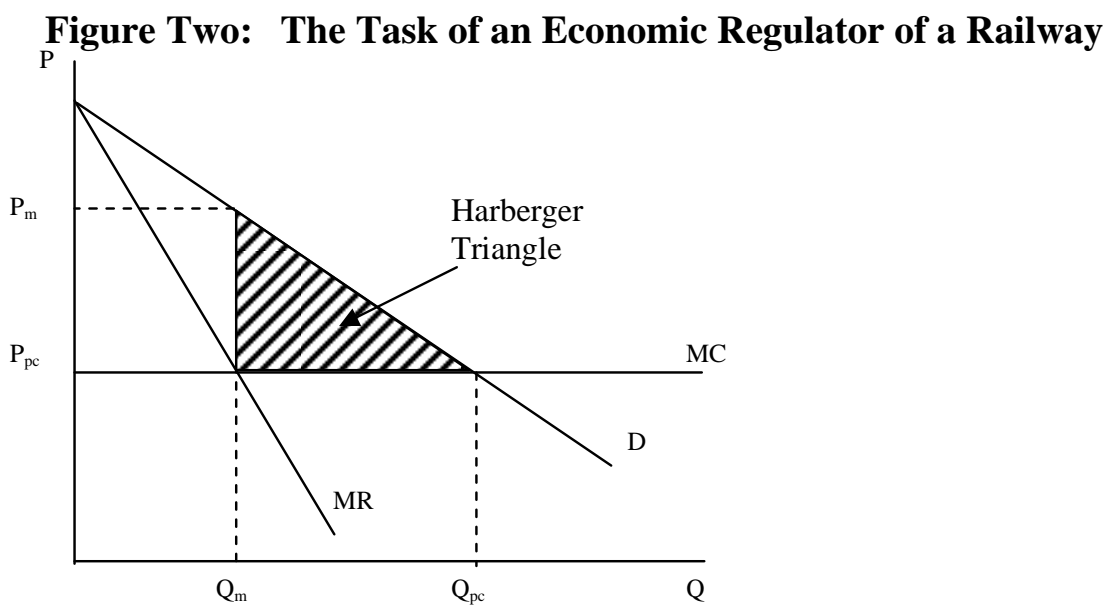

As in other utilities, regulators of railways endeavour to minimise the size of the Harberger Triangle by bringing the price of the service of the monopolist track infrastructure owner $\left(\mathrm{P}_{\mathrm{m}}\right)$ closer to the competitive level $\left(\mathrm{P}_{\mathrm{pc}}\right)$ in order that this might induce supply $\left(\mathrm{Q}_{\mathrm{m}}\right)$ to move out to the competitive level $\left(\mathrm{Q}_{\mathrm{pc}}\right)$. The regulator does this by setting a revenue or price cap. The former is used in railways, to allow the railway owners to price discriminate in an efficient fashion, whilst the latter is used where the good being transported is more homogenous, like electricity or gas.

In doing this, regulators face two immediate problems. ${ }^{3}$ Firstly, inefficiencies associated with monopoly production may manifest themselves through overcapitalisation or bloated costs, rather than through excess profits. Thus, rather than using the actual cost function of the railway being regulated, regulators use a model of a 'best practice' railway. Secondly, railways have high fixed and sunk costs. Prices based upon short-run marginal costs will be insufficient to cover sunk and fixed costs and hence future investment or maintenance of existing capital assets would become impossible. Thus, regulators endeavour to set prices at a level equal to the minimum of the long run marginal cost curve. This process, in principal at least, is designed to provide incentives for efficient investment.

The actual regulatory process may be described as follows. Firstly, the regulated railway puts forward a proposed Access Agreement (AA), which outlines the proposed prices (actually, revenue projections in the case of rail) and terms of access. The form this proposal takes is set out in the governing legislation; regulated firms must build revenue projections from 'building blocks' such as the asset base, capital and operation expenditure and the weighted average cost of capital (WACC). Each 'building block' must be justified with supporting information. The proposed AA then becomes a public document, and other stakeholders are invited to comment. Commonly, customers of the railway do so, attacking or supporting the various 'building blocks' the railway owners have put forward. Comments also usually become public documents. ${ }^{4}$ The regulator then releases a Draft Decision, outlining its opinions in relation to each of the points in the proposed AA and inviting the railway owner to revise its proposed AA accordingly. This is followed by a further round of

\footnotetext{
${ }^{3}$ They face a great many more problems, such as difficulties in estimating marginal cost, but for the moment, we consider only these fundamental issues.

${ }^{4}$ Both access providers and access seekers generally have a right to declare certain information provided to the regulator as 'commercial in confidence', and this is not made public.
} 
consultation, a revised AA and a Final Decision by the regulator. The railway owner can either accept the Final Decision, or exercise its right to a court determination. A full description of the process can be found at www.era.wa.gov.au. Other Australian regulators follow a similar process when called upon to make a determination in the industries they represent.

\section{Is the Process Objective?}

The process described above, with its focus on dry economic 'building blocks' such as WACC and asset values, appears at face value to be an objective application of economic theory and data with a clear function to be optimised. There may be a great deal of discussion between the regulator, the regulated railways and the customers of the railway, but this is in the character of information gathering by the regulator to inform the Draft and Final Decisions, rather than any form of consensus-building process as would occur in a parliamentary setting.

However, is the decision really objective, the optimisation of a resource allocation function set out in the legislation, or does it just appear to be? The answer turns on the issue of forecasts. The regulator, as discussed, builds a model of the 'best practice' railway, which is then forecast forward through the regulatory period in order to provide appropriate revenue or price caps. Forecasts are based upon two things; data and assumptions. The former are objective and the latter are not, a distinction which will be made clearer in the discussion below. It is an important distinction to make, because data alone rarely provide unequivocal results. Rather, some assumptions are usually needed to establish preferred results.

By way of a very simple example, consider the series of numbers $1,3,5,7 \ldots$ and the set $\{9,10,11,12\}$. Which, of the set $\{9,10,11,12\}$ is the next in the series? Many would suggest that nine is the next number, as the series contains odd numbers, and nine is the next odd number. However, it is possible to construct a valid argument for any of the set $\{9,10,11,12\}$ as the appropriate next number in the series. This is because a polynomial of order $n$ can be fitted to any series of $n$ numbers. For example, in the above cases, the following formulae hold (where $y$ refers to the result and $t$ to the observation number; for example $t=5$ is the $5^{\text {th }}$ in the series):

$$
\begin{array}{ll}
y=\{1,3,5,7,9\} & y_{i}=-1+2 t \\
y=\{1,3,5,7,10\} & y_{i}=\frac{-680}{461}+\frac{4697}{1844} t+\frac{29}{3688} t^{2}-\frac{179}{1844} t^{3}+\frac{63}{3688} t^{4} \\
y=\{1,3,5,7,11\} & y_{i}=-\frac{899}{461}+\frac{2853}{922} t+\frac{29}{1844} t^{2}-\frac{179}{922} t^{3}+\frac{63}{1844} t^{4} \\
y=\{1,3,5,7,12\} & y_{i}=-\frac{1118}{461}+\frac{6715}{1844} t+\frac{87}{3688} t^{2}-\frac{537}{1844} t^{3}+\frac{189}{3688} t^{4}
\end{array}
$$

Indeed, even if the series were $y=\{1,3,5,74532187\}$, one could express this by the following fourth-order polynomial:

$$
y_{i}=-\frac{992547443}{461}+\frac{2286485645}{922} t+\frac{65716581}{1844} t^{2}-\frac{405629931}{922} t^{3}+\frac{142763607}{1844} t^{4}
$$


Each of the models above is equally correct, which means that each forecast $(9,10,11,12$ or 4532187$)$ is also correct. The situation an economic regulator faces is much more complex than a series of numbers like 1,3,5,7, but the principle remains the same; economic theory can assist in constructing a model, but if the model produces several results when objective data are fed into it (or if several models are equally valid), economic theory cannot necessarily assist in determining which is correct. In this case, subjective assumptions will need to be made concerning some of the inputs in order to form a judgement about which is the best answer. A subjective assumption is underpinned by the preference or preferences of those who make it; a preference for simplicity in the above number series causes most people to judge that the model predicting nine is the best model.

However, a judgement is not a fact, and thus it is no longer valid to speak of the regulator objectively optimising the resource allocation function established by Parliament. Instead, when an economic regulator needs to use subjective assumptions in order to reach an outcome, he or she must take into account the preferences of at least some of the parties to the regulatory process, and is thus no longer making a bureaucratic decision, but a political one. Economic regulation, in other words, is a special form of a social choice mechanism, and subject to the same conditions and limitations as all social choice mechanisms. The consequences of this are discussed below, in a model which forms the centre of this paper. First, however, it is useful to examine some general results for social choice mechanisms.

\section{Social Choice Mechanisms}

This section describes two results pertaining to social choice mechanisms. The first of these, Arrow's Impossibility Theorem, is a general result, pertaining to the class of all social choice mechanisms. The second, the model at the centre of this paper, is an application of Arrow's Impossibility Theorem to the case of economic regulation.

\section{Arrow's Impossibility Theorem - the General Case}

Perhaps the most pervasive theory within the social choice literature is Arrow's (1950) "Impossibility Theorem". Starting from the position that a social choice mechanism should be judged by its consequences for individuals, Arrow endeavoured to discover whether there is some way in which one can aggregate rational individual preferences into a rational social preference function. His now famous "Impossibility Theorem" shows that there is not. The theorem is based upon a number of conditions, which Arrow shoed cannot be simultaneously satisfied. These, as summarised in Arrow (1998) are as follows: ${ }^{5}$

- Universality: the social choice mechanism is defined and transitive over all logically possible profiles of preference orderings over the set of alternatives.

- Monotonicity: If $A \prec B$ in some social preference ordering, and $A$ is raised in an individual preference profile, $A \prec B$ holds in the new social preference profile.

- Independence of Irrelevant Alternatives: If all individuals have the same preference ordering for some set of alternatives, then the social preference ordering of these alternatives will be the same, regardless of preferences over other (irrelevant) alternatives.

\footnotetext{
${ }^{5}$ The original formulation of these conditions, in Arrow (1950) was not quite correct, hence the use of the more recent formulation.
} 
- Non Imposition: A social preference mechanism is not imposed. That is, there is not some pair of alternatives for which the social choice is the same, regardless of individual preference orderings.

- Non-Dictatorship: The social preference schedule is not imposed by an individual's preferences, regardless of the preferences of other individuals.

One can replace monotonicity and the independence of irrelevant alternatives with the Pareto principle; that is every individual has the relation $A \prec B$, then $A \prec B$ holds in the social preference relation as well. The results are almost identical; imposition of the Pareto principle merely removes the possibility of negative dictatorship, where the social choice is never the outcome the dictator wants. The result of the theorem is that a social choice mechanism results in either a social choice which is completely unreflective of the individual preferences which exist in the relevant group, or a dictatorship by a single individual.

Arrow's theorem has generated thousands of papers in response. Most of these seek to prove it is untrue, or to describe conditions in which impossibility can be overcome. Broadly speaking, the literature may be divided into two parts. Firstly, there are the papers which examine the very fundamental notions underpinning Arrow's theory. Secondly, there are the papers which endeavour to relax or change one or other of the conditions, to examine the results of doing so. It would be impossible in this paper to do justice to the literature. However, below I summarise some of the results in each field, where they pertain to the central task of this paper.

Buchanan (1954) attacks the link between individual preferences and social preferences, suggesting that the link from individual to social rationality is in error, and that social rationality cannot be compared with the rationality of individuals in the group; one is in effect talking about two different things and just because individual preferences do not provide a 'measuring stick' does not mean that one does not exist. The problem with an approach whereby the social good is divorced from individual preferences is that it becomes, as Feldman (1980) suggests, a rather barren and empty concept. Moreover, as Plott (1976) notes, it is not just whether individual and social good are connected that is the issue; any social choice mechanism that requires some form of internal consistency is likely to face problems of impossibility. ${ }^{6}$

Sen (1995) suggests that a better approach might be to look not at consequences and outcomes, but rather at procedures and institutions; what kind of outcomes do our institutions give us, and are they appropriate. This, as he notes, is completely different to the standard economic analysis involving utility analysis, whereby procedures and institutions are a side issue; a means by which we get to the heart of the analysis, social welfare. Some of the conclusions of this paper can be interpreted in the context of looking to procedures and institutions, rather than welfare maximisation, in order to address issues associated with economic regulation.

Plott (1976) provides a comprehensive account of attempts to overcome Arrovian impossibility by altering or weakening the conditions which underpin it. One might,

\footnotetext{
${ }^{6}$ Buchanan (1954) is not particularly concerned with consistency, arguing that the ability of majority vote legislatures to experiment with outcomes and then reverse decisions later is precisely their strength. This strength, however, is a product of a lack of information about outcomes, and it does not seem unreasonable to require some consistency over outcomes which are known.
} 
for example, define a social choice mechanism over only some preference relations, or leave some preference relations undefined. Leaving aside the question of how one might decide which preference relations to ignore, the end result of doing this is that dictatorship is defined over 'free triples'; groups of three outcomes which are not restricted by having a preference relation ignored. This provides a little extra freedom, but the fact that the free triples might overlap limits the freedom substantially. Moreover, as the number of players in the game, and their heterogeneity of preferences increases it becomes progressively more difficult to find cases where impossibility does not influence results.

One could also relax transitivity, ${ }^{7}$ and either make it weakly transitive, or replace it with the condition that there is no cyclicality. However, the former results in Arrow's dictator being replaced by an oligarchy, and the latter results in numerous 'collegiates' forming, any two of which can impose their will on the remainder of society. This is an improvement, but not a very substantial one.

One could also relax the independence of irrelevant alternatives condition, and allow preferences to change as the set of possible outcomes changes. As Plott (1976) notes, this is akin to replacing preferences with standards; things one will accept rather than things one likes. It also shifts the focus from outcomes to behavioural patterns and constraints. However, as soon as one endeavours to impose some form of constraint on the consistency of choices in the sets, impossibility begins to become an issue.

Before moving to the model which lies at the centre of this paper, it should be noted that it is possible to relax one final assumption of Arrow. Arrow was looking for the most general results he could, and so he made no explicit assumptions about utility. Specifically, he did not assume that it was cardinal and comparable. The utility theory of $19^{\text {th }}$ Century economics had been underpinned by cardinal and transferable utility, but this had fallen from favour as a means of describing utility by the mid- $20^{\text {th }}$ Century, because, as Sen (1995) notes, there is no scientific basis for interpersonal comparisons of utility. However, if one assumes cardinal, transferable and comparable utility, then the problem of impossible preferences vanishes, as one can compare the preferences of each party and maximise their sum (or social welfare). Note that utility must be both cardinal and comparable in order for this to occur.

\section{A Model of Regulation as Social Choice - The Special Case}

If economic regulation is a form of social choice mechanism, how might we adapt the results of Arrow's Impossibility Theorem above to suit the circumstances of economic regulation and public management? Note first that economic regulation is a revelatory process. Whilst all parties understand from the outset that the regulator wants an outcome with no monopoly rents, the regulated railway wants to maximise revenues and each customer wants to minimise price, it is only by going through the process that each party understands what the other parties mean in the context of these broad statements. Note also that, unlike the pure Arrovian framework, utility is not entirely ordinal and non-comparable. Some aspects of the utility of each party in the regulatory process is cardinal and comparable. For example, the railway and its customers each make profits, in dollars, which they report to various bodies.

\footnotetext{
${ }^{7}$ Plott (1976) does not define monotonicity as a separate item, as Arrow does. Rather, it is implied by the way in which transitivity is defined.
} 
To formalise the model a little, assume that there are three players; the regulator, the regulated firm and a representative customer. Assume there are $n$ possible outcomes of the regulatory process, each of which is discreet and mutually exclusive. Each player forms a preference schedule, consisting of an ordering of the $n$ outcomes. Assume that these preference schedules follow the same axioms as in Arrow (1950), namely universality and monotonicity in preferences and independence to alternatives irrelevant to a given preference choice.

During the course of the regulatory process, each party reveals its preference schedule to each other party through the provision of information, which underpins the forecasts each party makes as to the 'best' revenue or price cap. Reflecting the nature of utility in the game (described above), there are two types of information:

- Objective information: which can be objectively assessed by, quantified by and compared between all players in the regulatory game.

- Subjective information: which is either private to a player or, if public, cannot be meaningfully compared between players, nor objectively assessed by them.

Profit streams are an example of the former, whilst the differing views between the NCC and BHP (see NCC, 2005) concerning the impacts of third parties on BHP's existing operations in the Pilbara are an example of the latter. Note that there is no requirement for any party to reveal all of its objective or subjective information. All that is required is that each party is able to develop an understanding of the preference schedule of the other two.

The mapping of the utility associated with each outcome into the information set is one-to-one. In other words, the two concepts are synonymous; information is merely a way of describing utility. The difference between the two types of information is the mapping; the objective information mapping is one-to-one and common knowledge, whilst the subjective information mapping is one-to-one and private. One consequence of this is that the objective information is always truthful, whilst the subjective information need not be; it could include lies and ambit claims.

Through the information each party reveals from its private information set, each player learns of the preference schedule of other players, and individual preference schedules are then combined to form the regulatory outcome, or social preference schedule. Arrow's Theorem is carried into the analysis by the following conjecture: ${ }^{8}$

- If the preference ordering of each party can be completely described using only objective information, then it is possible to map from individual preference schedules to the social preference schedule.

- If subjective information is decisive in describing the ordering of a party (that is $A \prec B$ with objective information but $B \prec A$ with subjective information) then Arrow's Impossibility Theorem holds.

Note that the first case, where only objective information determines an ordering is precisely the scenario whereby a parliament can devise a function a bureaucratic agent can effectively organise. Problems arise in the second case where it is sufficient for subjective information to influence the orderings of only two outcomes for one player

\footnotetext{
${ }^{8}$ The proof of which is still a work in progress.
} 
in order for impossibility to hold. The threshold is not very high, and thus it seems highly likely that a regulatory decision will be affected by impossibility. It remains to examine the consequences of impossibility in regulatory determinations, which is the task of the following section.

\section{Consequences of Regulatory Impossibility}

Arrow's Impossibility Theorem suggests two possible outcomes of a social choice mechanism; either one party becomes an Arrovian dictator or the social choice mechanism is unreflective of any individual preference schedule, or any combination of individual preference schedules. It is not clear which outcome will obtain as a matter of general principle in the case of economic regulation. However, each contains potential problems from the perspective of public policy.

The dictatorial outcome seems both easiest to understand (one party will prevail) and conceptually the least attractive. Although a regulatory decision can be appealed in court, the economic regulator seems most likely of the three parties to become a dictator because there is an asymmetry between it and the other parties in terms of their abilities to impose outcomes; the regulator is more able to enforce its will.

Seen from this perspective, it is little wonder that firms facing economic regulation are not particularly enthusiastic about the idea. However, the owners of the infrastructure are not the only parties who might be hostile to an access regime. Quinet (2006) describes how opposition from unionised French railway workers has slowed the implementation of third party access in France. These workers are not alone, and reflect a relatively common phenomenon in publicly-owned railways, where the workers of the railway have become important stakeholders, and may potentially lose in a system whereby any conflict with the economic regulator on resource allocation decisions will be lost. Future stakeholders might also be affected. Consider the case of a shipper. If, at present, this shipper is unable to obtain access at all, then a loss of future decision-making ability over the infrastructure might not be a large issue. However, above and below-rail infrastructure are complementary, and decisions made below rail affect the range of possible decisions made above-rail. This could change the risk-profile of the above-rail firm, and influence its decision to integrate upstream into train operations rather than buying a rail service.

The unreflective social preference outcome seems less sinister than the dictatorial outcome. It is not clear a priori how the social preference schedule will be formed, but it seems most likely that it will be formed through a process of negotiation between the three parties in the regulatory process, each of whom will have to move from their preferred situation in order to achieve an outcome. This seems relatively mild, and is indeed what one might expect in a bargaining situation. However, it results in two important consequences.

The first of these is that one cannot have marginal cost pricing, unless the regulator does not know the marginal cost of the firm being regulated (and hence the result is obtained purely by chance) or unless the regulator lies. If the regulator knows the true marginal costs of the firm then, since that information originates with the firm, it must by definition be objective information. If the regulator uses this information, others (particularly the regulated firm) will know it is objective and will hence seek to negotiate away from the position where prices equal marginal costs. If the regulator 
achieves an outcome where price equals marginal cost, then the others have failed in their negotiations and hence the regulator is a dictator. ${ }^{9}$ If he does not, then, as Lancaster \& Lipsey (1956) show, there is no guarantee the outcome will be welfareimproving compared with the unregulated position. If the regulator somehow manages to obscure the fact that it knows the regulated firm's marginal costs and thus succeeds in credibly using only subjective information about the firm's costs, it might be able to negotiate towards marginal cost pricing. Quite how the regulator might achieve this obfuscation is unclear but, even if it is successful, if the deception is uncovered at a later stage, this could risk the perception of the regulatory process as objective and impartial, which impacts its usefulness as a process.

The second issue is that unreflective social preferences mean that the parties to the regulatory process cannot ascertain its outcome even with full knowledge of the information sets of the other parties, let alone when some are acting strategically. The outcome will only be seen once negotiations are all complete. For some players, this may increase risk by an amount sufficient to make the game not worthwhile. Thus, as in the case of dictatorial outcomes above, there could be less entry above-rail than might optimally be the case. This could be improved upon by specifying the negotiation process more clearly in order that uncertainty is reduced. However, once the subjectivity cat is out of the bag, it may in fact be more optimal for policymakers to determine a different system entirely, which puts the social choice nature of economic regulation at the centre of the system, rather than at its periphery. This notion is expanded upon in the conclusions to the paper.

The discussion above is, in a sense, static. It describes what transpires each time the regulatory process occurs. However, regulation also evolves over time. This is discussed further below.

\section{Regulatory Evolution}

The aspects of the above discussion which made the regulatory process static were the sets of objective and subjective information. If these remain the same, each time the regulatory process is repeated, the same outcomes will obtain. The actual levels of the price or revenue caps might alter, as different negotiated outcomes are reached, or the external environment changes, but the set of decisions themselves will not change, and nor will the relationships between the parties.

However, if the sets of subjective information change such that something which was subjective for a given party becomes objective, ${ }^{10}$ then regulation evolves. There are a number of reasons why this might occur. The first is that, as history progresses, the degree of understanding of the industry and processes within it by the regulator (and indeed other parties) might change, by being able to observe the outcomes associated with particular decisions. Also investments which were speculative at one regulatory decision might have occurred by the time the next occurs.

There may also be a strategic factor at play. The regulator suffers from an information asymmetry in respect of the regulated firm (and conversely, though I

\footnotetext{
${ }^{9}$ One might, conceptually, imagine the regulator 'trading away' something else, but this does not help, as service quality, demand and cost are all tied together.

${ }^{10}$ Or vice versa, although it is not clear how such a process of forgetting would operate.
} 
focus on the former here). The regulated firm may find that it is in its interest to reveal objective information about its cost structure, when doing so results in the regulator making decisions which favour it and to hide this information otherwise. As discussed previously, the regulator may also find it useful to hide what it knows. However, the more information the regulator has, the more objective information becomes public, potentially, the more decisions can be made using that information outside the firm. This presents a catch 22 for both the regulator and the regulated firm; if the firm reveals more information, it might clear up some of the subjectivity formerly present in regulation which is more likely to make the regulator a dictator. However, at the same time, more information may lead to regulation creep; over time, preservation of light-handed regulation might be very difficult.

The historical record gives some credence to this conclusion. Hoogenboom \& Hoogenboom (1976) chart the history of the Interstate Commerce Commission (ICC) in the US which, over the hundred years of its history prior to the Staggers Act reforms of 1980, saw gradual increases in regulatory oversight until it effectively ran the rail industry in the postwar period, giving railways almost no freedom to react to changing circumstances. The solution in the US case was to radically wind back regulation, and to make it very difficult for the ICC (and its successor after 1996, the Surface Transportation Board - STB) to impose regulation. In the closing years of the $19^{\text {th }}$ Century and early years of the $20^{\text {th }}$ Century in the UK, the Railway Commissioners Court and its successors (see McWilliams, 1923) faced a similar expansion in role, but the eventual solution was the other logical conclusion, the nationalisation of the British rail system in 1948.

If the social decision mechanism of economic regulation results in unreflective social preferences and decisions made by negotiation, then the effects are different. In a negotiation process, objective information (or more specifically, the ability to continue supplying it) is power. Thus, private information may held back in early regulatory decisions and released strategically in later rounds to improve the power of a party in the negotiations. Since the regulated railway knows more about the costs of the infrastructure being regulated than the other two parties, it would seem to have the greatest incentive to act in this strategic manner. In cases where there are many customers, each of whom can benefit only slightly from strategic behaviour, the regulated railway may also find it easier to sustain strategic action than its customers. Stigler (1971) describes this process of seeking to influence the regulator as 'regulatory capture'. However, this process of regulatory capture is something of a double-edged sword for the regulated railway. As objective information is brought into the public domain, it may be used to make more decisions pertaining to the operations of the railway than was possible when this information was private to the railway owner. Such collective decision-making may not be in the best interests of the infrastructure owner.

Thus, as information sets change their characteristics, one might expect to see regulation evolve. Regardless of whether the regulator becomes a dictator or whether the social preference mechanism is unreflective, there is a distinct risk of regulatory creep; of the set of private decisions made about the railway becoming smaller and the set of public (or regulatory) decisions becoming larger. The speed of this creep will depend upon how tightly the legislation governing the regulator binds its ability to act 
with discretion (with tight rules introducing problems of inflexibility) and upon how each regulator perceives its role in respect of the industry.

The evolution of a given regulatory system may in fact be cyclical, with periods of regulatory expansion, followed by a period of deregulation (or nationalisation). Indeed, it would seem that the US has completed one cycle already, and is moving on to the second. In the hundred years to 1980, regulatory control over the railways became increasingly tight, until the railways could no longer effectively function. A sharp period of deregulation followed, and over the past 25 years, the railways have reformed their operations and consolidated their profitability. Now, concerns are arising that the last few years of good profits are indicative of rising monopoly power, and a bill is before the $110^{\text {th }}$ Congress (House Bill 2125 - the Railroad Competition and Service Improvement Act 2007) to impose more regulation on the industry, ostensibly to improve 'competition' for shippers.

Likewise, the UK went through an increase in regulation which ended in nationalisation, and deregulation roughly half a century later. It has subsequently renationalised its below-rail infrastructure, although it is not clear whether economic regulation is becoming more pervasive. Australia, with its century of public management by bureaucracy has deregulated only recently, and hence the wheel, if it is turning at all, has only started to do so. However, already, policymakers are endeavouring to implement a unique experiment and extend third party access to private railway infrastructure on a system-wide basis. ${ }^{11}$

Such cyclicality need not be an issue, particularly since regulation changes anyway as the environment in which firms operate alters over time. However, rail assets are long-lived, and if regulatory cycles are short (or uncertain) then this might increase regulatory risk. For the sustainability of the industry, it is not clear that this kind of cyclicality is particularly useful.

\section{Conclusions and Policy Suggestions}

In his original paper on the Impossibility Theorem, Arrow (1950) suggested four ways in which resource allocation decisions in a society might be made:

- By the market.

- By a dictator.

- By voting.

- By convention.

A very common means of determining the allocation of resources with a public good component (where the market is unsuitable) in societies today is for the relevant parliament to design a 'resource allocation function' which is then objectively optimised by appointed agents from the bureaucracy. This is a subset of Arrow's category above of management by convention, with the convention clearly delineated in the legislation governing the task of the particular regulator or public manager. However, as this paper has shown, unless the relevant regulator or public sector manager works in an environment where subjectivity is not decisive in determining preference orderings, the convention does not work. In actual fact, what is created is

\footnotetext{
${ }^{11}$ North American regulators have imposed access regimes on certain items of private infrastructure, but not a whole system, as is being proposed in the Pilbara.
} 
either a dictatorship, or a different type of convention, but one where those external to the regulatory process have no idea how social preferences are formed. Since almost all regulation and public management involves forecasts subject to Knightian uncertainty, it seems somewhat unlikely that there will be many cases where the failure does not occur.

Two questions arise from this; “does it matter?” and “can we do things any better?”.

In examining the question of whether it matters of not, consider first, the case where the regulator becomes a dictator. The result might be termed the 'dictatorship of the professionals' since the agents are usually chosen for their professional abilities in the relevant field. This is not to say that such dictatorship is a bad outcome.

Professionals within a bureaucracy may make resource allocation decisions, and bring great benefits to the society in which they work. However, one must always remember that, whilst it is their objective skills that give professionals their status in their given field, it is their subjective judgement which makes them dictators.

If the resource allocation process is unreflective of individual social preferences, then one no longer has dictatorship by professionals. However, nor does one have the resource allocation mechanism designed by Parliament. Instead, one has a convention which, potentially, society at large knows nothing about; a convention which has been created within the industry or sector of the economy which is regulated or operated by public sector bureaucrats. Again, the conventions which have been developed may well serve society well. However, no-one outside the sector necessarily has any idea what they are, except that they are not (precisely) what the legislation governing the industry or sector says they should be. As Stigler (1971) points out in respect of regulatory capture, those with the greatest stake will endeavour to write the rules in their favour. This should be of concern when the conventions made inside an industry or sector result in resource allocations which affect society as a whole.

If one is concerned about dictatorship by professionals, or by the fact that, since the conventions in each 'resource allocation mechanism' designed by a parliament cannot work, one has little idea what conventions are governing a resource allocation decision, what else might one do? From Arrow's list above, one has three choices; to endeavour to bring the relevant decisions to the market, to vote on them or to design a different convention. ${ }^{12}$

Resource allocation decisions sit outside the market due to some form of market failure. In the case of economic regulation, it is market power. The solution to this could be to design the market better, such that it can accommodate the resource allocation decisions with no market failure. However, in many instances, this may be very difficult. For example, economic regulation exists precisely because the monopoly being regulated is 'natural', and competition is so hard to introduce. Also, addressing issues such as externalities or information asymmetries involves designing better property rights regimes. The designers themselves face the same problems as the regulators and public managers described in this paper; if parliament charges them to design a set of market rules, they will be unable to act solely in an objective fashion

\footnotetext{
${ }^{12}$ We could also appoint a different dictator, but that dictator would also use subjective judgement and cause the same problems. In any case, it would seem intuitively more appropriate in a democracy to avoid dictatorial solutions.
} 
in the same way that regulators and public managers cannot. Thus, there may be some, but limited scope for designing a market. There is, however, still a great deal of utility to be gained from using the market as a benchmark. Sonnenschein (1974) provides an axiomatic treatment of a competitive market as a choice mechanism. Thus, if a choice process is designed and fully described in terms of its axioms, one can compare it with the competitive market benchmark and examine whether the two are axiomatically equivalent.

The second choice is to put the issue to a vote. Such a vote could either take the form of a plebiscite, or the vote could occur in a parliament, amongst the elected representatives of the populace. The first option is problematic because of the scale of the task; even if railways were the only industry with resource allocation decisions which were in the public interest, the number of plebiscites would quickly become unworkable. There would have to be some cut-off point whereby the railway managers would make the 'day-to-day' decisions. The choice of a cut-off position, however, raises the same problems of objective resource allocation functions that are the subject of this paper. If the vote occurs in a parliament, the same problems arise, and another is added; that of politicisation of the decision-making process. In fact, it was to avoid precisely this problem that control of railways was taken away from parliament in Australia in the late $19^{\text {th }}$ Century. Thus, voting does not seem to be a particularly effective alternative.

The final alternative is to try a different form of convention. In the context of railways, economics does not seem to be particularly useful for convention-building, because it gives rise to a process which appears objective, but which is not. It might be useful to step outside economics, and examine other forms of convention-building. A companion paper (Wills-Johnson, 2007) describes a potential paradigm in more detail, but it is based around taking the main focus of economic regulation away from monopoly rents, and towards sustainable management of the relevant asset in question. This requires a very different role for regulators and most especially the regulated firm. ${ }^{13}$ The basic premise around sustaining the asset is rooted in Hardin's (1968) tragedy of the commons, and the solutions in co-operative game theory. Sethi \& Somanathan (1996) show how this requires the development of 'social norms'. In other words, one moves from welfare analysis to examining the institutions and procedures noted by Sen (1995). For bureaucrats, accustomed to dealing with deterministic rules devised by parliaments, organic development of social norms may be uncomfortable. However, there are many signs that it can work. In the railway industry in Australia, the Hunter Valley Coal Chain Logistics Team, is one practical example. More broadly, as Ostrom (1990) and Bromley (1992) document, history provides literally thousands of examples of similar approaches, which have sustained resources over centuries. The basic approach may yet prove feasible for the sustainability of the rail industry as well.

\footnotetext{
${ }^{13}$ In fact, a variant of rate of return regulation would seem more appropriate, with the rate agreed amongst all parties.
} 


\section{Bibliography}

Arrow, KJ (1950), “A Difficulty in the Concept of Social Welfare” Journal of Political Economy 58(4) $328-46$.

Arrow, KJ (1998) “Arrow’s Theorem” in Eatwell, J, Milgate, M \& Newman, P (eds) The New

Palgrave Dictionary of Economics Vol1, MacMillan Press: London 124-6

Bromley, DW (ed) (1992) Making the Commons Work, ICS Press; San Francisco

Buchanan, JM (1954) “Social Choice, Democracy, and Free Markets”, Journal of Political Economy, 62(2) $114-23$

Feldman, A (1980) Welfare Economics and Social Choice Theory, Martinus Nijhoff Publishers: Boston

Hardin, G (1968) “The Tragedy of the Commons”, Science, 162 (3859) 1243-8

Hoogenboom, A \& Hoogenboom, O (1976) A History of the ICC: From Panacea to Palliative, WW Norton \& Co, New York.

Lancaster, K \& Lipsey, RG (1956) “General Theory of Second Best”, Review of Economic Studies, 24(1) 11-32.

McWilliams, RF (1923), “The Future of Railway Control”, Quarterly Journal of Economics, 38(1) 3153.

National Competition Council (NCC) (2005) Application by Fortescue Metails Group Limited for Declaration of a Service Provided by the Mount Newman Railway Line: Draft Recommendation November 2005 Canberra NCC

Ostrom, E (1990) Governing the Commons: The evolution of institutions for collective action, Cambridge Uni Press; Cambridge UK

Plott, CR (1976) “Axiomatic Social Choice Theory: An overview and interpretation”, American Journal of Political Science, 20(3) 511-96

Quinet, E (2006) “France: Avoiding competition” in Gomez-Ibanez, JA and G De Rus (eds) Competition in the Railway Industry: An international comparative analysis, Edward Elgar; Cheltenham UK 81-110

Sen, A (1995) "Rationality and Social Choice”, American Economic Review, 85(1) 1-24

Sethi, R and Somanathan, E (1996) "The Evolution of Social Norms in Common Property Resource Use”, American Economic Review, 86 (4) 766-88

Sonnenschein, H (1974) “An Axiomatic Characterization of the Price Mechanism”, Economterica, 42(3) 425-34

Stigler, GJ (1971) “The Theory of Economic Regulation”, Bell Journal of Economics and Management Science, 2(1) 3-21

Wills-Johnson, N (2007) Conveyor Belt of Competitive Market: What is a railway (August 2007). Available at SSRN: http://ssrn.com/abstract=1010261 